\title{
Spontaneous Switching between Permeability Enhancement and Degradation in Fractures in Carbonate: Lumped Parameter Representation of Mechanically- and Chemically-Mediated Dissolution
}

\author{
HIDE YASUHARA ${ }^{1}$, DEREK ELSWORTH ${ }^{1, *}$, AMIR POLAK $^{2}$, \\ JISHAN LIU ${ }^{3}$, AVRAMI GRADER ${ }^{1}$ and PHILLIP HALLECK ${ }^{1}$ \\ ${ }^{1}$ Department of Civil and Environmental Engineering, Ehime University, Matsuyama, \\ 790-8577, Japan. \\ ${ }^{2}$ Department of Civil Engineering, Technion, Haifa, Israel \\ ${ }^{3}$ Center for Oil and Gas, University of Western Australia, Perth, WA, Australia
}

(Received: 18 May 2004; accepted in final form: 28 December 2005)

\begin{abstract}
Principal mechanical and chemical processes contributing to the observed spontaneous switching from net decrease in permeability to net increase in a fracture in carbonate are examined. The evolution of permeability, and related fracture aperture, is represented through a lumped parameter model. The significant processes of pressure solution beneath bridging asperities, transport of dissolved mass to the fracture void, and subsequent precipitation or dissolution within the fracture void enable the principal characteristics of observed behavior to be followed. The evolution of dissolved mass concentration in the pore fluid is followed for arbitrary applied stress, temperature, and $\mathrm{pH}$ conditions, with appropriate feedback to the evolution of fracture permeability. Comparisons with experimental measurements in limestone (Polak et al., 2004, Water Resour. Res. Vol. 40, W03502, doi: 10.1029/2003GL017575) show satisfactory agreement for the evolution of fracture aperture and to a lesser degree in calcium concentrations in the effluent pore fluid. Importantly, the spontaneous switching in permeability change, from aperture reducing to aperture increasing, with no change in environmental conditions, is replicated without the need for an ad hoc trigger. Although this switch is accurately replicated, the lumped parameter model is incapable of replicating the rapid observed growth in permeability that directly follows. This inability results from the assumed form of the lumped asperity model, that is incapable of representing the spatially distributed change in aperture that is seen to occur within the fracture. Despite this inconsistency, the model is shown capable of representing the principal behaviors evident in the response.
\end{abstract}

Key words: dissolution, precipitation, permeability, fracture, pressure-solution, carbonate. 


\section{Introduction}

An understanding of the flow and transport characteristics of fractured rocks is crucial to the effective recovery of potable water, and mineral and energy resources from the subsurface, and for the safe isolation and containment of hazardous materials. The influence of mechanical and chemical effects on the permeability of fractured reservoirs is well known, however the interaction between mechanical and chemical influences is poorly understood. This is particularly true in fractured media, where bulk permeability is strongly conditioned by changes in fracture opening or closure, in-turn effected by changing fields of stress or chemical potential.

Current observations indicate conflicting predictions of changes in fracture permeability under applied temperatures and stresses with net dissolution, dependent on the specific site of dissolution. Permeability may increase as the fracture void is etched by net dissolution, or may decrease as mass is predominantly removed from beneath bridging asperities. Sealing is reported in some instances at elevated temperature $\left(>300^{\circ} \mathrm{C}\right)$ in sandstone (Tenthorey et al., 2003) and in granite (Moore et al., 1994) and at modest temperature $\left(50-150^{\circ} \mathrm{C}\right)$ in tuff (Lin et al., 1997) and in novaculite (Polak et al., 2003), and under low effective stress $(0.2 \mathrm{MPa})$ with an acidic solution (Durham et al., 2001). Conversely, gaping is suggested in carbonate reservoirs (e.g. Liu et al., 1997; Dijk and Berkowitz, 2000; Dijk et al., 2002), and in the development of karst (e.g. Palmer, 1991; Polyak et al., 1998). Importantly, these opposing behaviors operate concurrently, but to varying degrees. Subtle changes in local conditions of applied stress or chemical potential may trigger switching between dominant mechanisms - note that "switch" is referred to as the meaning of transition between net decrease in fracture aperture (and related permeability) and net increase throughout this work. Thus, besides monotonic sealing or gaping of a fracture, the behavior may switch, either in response to changing stress or chemical conditions, or spontaneously, with no apparent trigger (Polak et al., 2004).

Describing the conditions that promote the observed behavior (i.e., spontaneous switching from aperture closing to aperture gaping in limestone) is the focus of this work, in defining and representing the competing rates of pressure solution and free-face dissolution that control the evolution of fracture aperture. Specifically, for the first time, we develop a mechanistic model capable of describing behaviors where fracture aperture (or permeability) reduces with net dissolution within a fracture in limestone (Polak et al., 2004), and this rate of permeability reduction is accelerated by a change in permeant. This complements prior diasnostic models of this observed behavior (Liu et al. 2005) and their extension to prediction (Liu et al. 2006) by defining response in terms of readily defined material properties (Yasuhara, 2005). Importantly, this model is also able 
to describe a spontaneous switch from permeability reduction to permeability enhancement, which occurs without any change in experimental conditions - these invariant conditions include no change in influent water chemistry, temperature, flow rate or ambient stress. This trigger is a feature of fracture architecture alone, and is capable of explaining the enigmatic behavior.

\section{Mechanistic Model}

In this work, a mechanistic model is presented to describe the dissolution-dependent evolution of a fracture aperture in rock that accommodates the competing processes of pressure (dis)solution and free-face dissolution. Fracture aperture (or related permeability) may decrease if pressure solution dominates, or may increase if free-face dissolution prevails. This model follows the three serial processes of interfacial dissolution beneath the contacting asperity indenter, mass diffusion along the indenter-interface, and subsequent precipitation within the fracture void, and additionally accommodates the role of free-face dissolution, in describing the observed spontaneous switching in fracture aperture from net closure to net gaping (Polak et al., 2004). This development is detailed in the following.

\subsection{RATES OF PRESSURE SOLUTION AND FREE-FACE DISSOLUTION}

The evolution of fracture aperture is controlled by the competing influences of pressure solution and free-face dissolution. Pressure solution within a fracture incorporates three serial processes; mineral dissolution at asperity contacts, dissolved mineral diffusion along the interfacial water film, and mineral precipitation at the pore wall, and may result in net reduction of fracture aperture. This results if the solubility of the solute is above the equilibrium concentration for the solvent. Conversely, if the mass rate of supply to the fluid occupying the fracture void is sufficiently low, or the flow system sufficiently open, then the solute concentration in the pore fluid will be below the equilibrium concentration, net dissolution will proceed, and the fracture will widen. The competition between pressure solution and precipitation in the fracture void, that together contribute to a net reduction in permeability, and dissolution from the wall of the fracture void, that will net increases permeability, will prescribe the dominant effect; either net sealing or gaping. Importantly, the dominant mechanism may change with stress and chemical condition of the solvent, or as a result of the evolution of fracture topography, and flow topology.

First, dissolution at the asperity contacts provides a source of mass into the fracture cavity, and is most conveniently defined in terms of a dissolu- 
tion mass flux, $\mathrm{d} M_{\mathrm{diss}}^{\mathrm{PS}} / \mathrm{d} t$, given as (Yasuhara et al., 2003) (for details, see Appendix A),

$$
\frac{\mathrm{d} M_{\mathrm{diss}}^{\mathrm{PS}}}{\mathrm{d} t}=\frac{3 \pi V_{\mathrm{m}}^{2}\left(\sigma_{\mathrm{a}}-\sigma_{\mathrm{c}}\right) k_{+} \rho_{\mathrm{g}} d_{\mathrm{c}}^{2}}{4 R T}
$$

where $V_{\mathrm{m}}$ is molar volume of the solid $\left(3.69 \times 10^{-5} \mathrm{~m}^{3} \mathrm{~mol}^{-1}\right.$ for calcite), $\sigma_{\mathrm{a}}$ is the disjoining pressure (e.g. Heidug, 1995) equal to the amount by which the pressure acting at grain-to-grain contacts exceeds the hydrostatic pore pressure, $k_{+}$is the dissolution rate constant of the solid, $\rho_{g}$ is the density ( $2710 \mathrm{~kg} \mathrm{~m}^{-3}$ for calcite), $d_{\mathrm{c}}$ is the diameter of the asperity contact, $R$ is the gas constant, $T$ is the temperature of the system, and $\sigma_{\mathrm{c}}$ is the critical stress, which defines stress state where the compaction of grain aggregate will effectively halt.

Second, based on Fick's first law and integrating it with respect to a circular contact of radius $r$ in the range $a_{0} \leqslant r \leqslant d_{\mathrm{c}} / 2$, diffusion along the asperity contact area is defined in terms of the diffusive mass flux, $\mathrm{d} M_{\text {diff }} / \mathrm{d} t$, as (Yasuhara et al., 2003),

$$
\frac{\mathrm{d} M_{\mathrm{diff}}}{\mathrm{d} t}=\frac{2 \pi \omega D_{\mathrm{b}}}{\ln \left(d_{\mathrm{c}} / 2 a_{0}\right)}\left(C_{\mathrm{int}}-C_{\text {pore }}\right),
$$

where $\omega$ is the thickness of the water film trapped at the interface, $D_{\mathrm{b}}$ is the diffusion coefficient, $a_{0}$ is an infinitesimal length (which we set to one-thousandth of the diameter of the initial asperity contact) substituted to avoid a singularity in integrating Fick's first law to the center of a circular contact area, and $\left(C_{\mathrm{int}}\right)_{x=a_{0}}$ and $\left(C_{\text {pore }}\right)_{x=d_{\mathrm{c}} / 2}$ are mineral concentrations in the interface fluid and pore space, respectively.

Finally, free-face dissolution/precipitation are quantified as mass fluxes, $\mathrm{d} M_{\text {diss }}^{\mathrm{FF}} / \mathrm{d} t$ and $\mathrm{d} M_{\text {prec }} / \mathrm{d} t$, defined by the dissolution/precipitation rate constants and difference between the fluid mass concentration in the pore space and the equilibrium concentration, defined as (modified from Dreybrodt and Buhmann, 1991; Palmer, 1991),

$$
\begin{aligned}
& \frac{\mathrm{d} M_{\text {diss }}^{\mathrm{FF}}}{\mathrm{d} t}=k_{+} A_{\text {pore }} \rho_{\mathrm{g}} V_{\mathrm{m}}\left(1-\frac{C_{\text {pore }}}{C_{\text {eq }}}\right)^{n}, \\
& \frac{\mathrm{d} M_{\text {prec }}}{\mathrm{d} t}=k_{-} A_{\text {pore }} \rho_{\mathrm{g}} V_{\mathrm{m}}\left(\frac{C_{\text {pore }}}{C_{\text {eq }}}-1\right)^{n},
\end{aligned}
$$

where $A_{\text {pore }}$ is the area of the fracture void, $k_{-}$is the precipitation rate constant of the dissolved mineral, and $C_{\text {eq }}$ is the equilibrium solubility of the dissolved mineral. $n$ denotes the reaction order, which is experimentally constrained (Dreybrodt, 1998): the reaction kinetics is roughly first order for a pore fluid undersaturated with calcium, and the reaction order increases 
as the water approaches saturation. In this preliminary model, the order is set to unity as a first approximation. Note that the dissolution/precipitation mass fluxes will be zero as the mass concentration in the pore fluid is either greater or smaller than the equilibrium solubility, respectively.

\subsection{CONTACT MODEL BETWEEN FRACTURE WALLS}

A single fracture is idealized as two rough surfaces held apart by bridging asperities, as illustrated in Figure 1 (left side). The average contact-area ratio, $R_{\mathrm{c}}$, may be determined by defining a representative contact area, $A_{\mathrm{c}}^{1}$, surrounded by an appropriate tributary area, $A_{\mathrm{t}}^{1}$, (Figure 1 ; right side), and is assumed equivalent to the ratio of the summed local contact areas, $A_{\mathrm{c}}^{\mathrm{t}}$, to the total fracture area, $A_{\mathrm{t}}^{\mathrm{t}}$, given as (Yasuhara et al., 2004),

$$
R_{\mathrm{c}}=\frac{A_{\mathrm{c}}^{1}}{A_{\mathrm{t}}^{1}}=\frac{A_{\mathrm{c}}^{\mathrm{t}}}{A_{\mathrm{t}}^{\mathrm{t}}}
$$

Within this tributary area, the contact diameter, $d_{\mathrm{c}}$, of the local contact area, $A_{\mathrm{c}}^{1}$, is defined as,

$$
d_{\mathrm{c}}=\sqrt{\frac{4 A_{\mathrm{c}}^{1}}{\pi}} .
$$

For uniaxial compaction, the normal forces acting on the tributary area and the contacting asperity balance, yielding the stress applied at the contact area, $\sigma_{\mathrm{a}}$, as,

$$
\begin{aligned}
& \sigma_{\mathrm{eff}} \cdot A_{\mathrm{t}}^{1}=\sigma_{\mathrm{a}} \cdot A_{\mathrm{c}}^{1} \\
& \Rightarrow \sigma_{\mathrm{a}}=\frac{\sigma_{\mathrm{eff}}}{R_{\mathrm{c}}},
\end{aligned}
$$

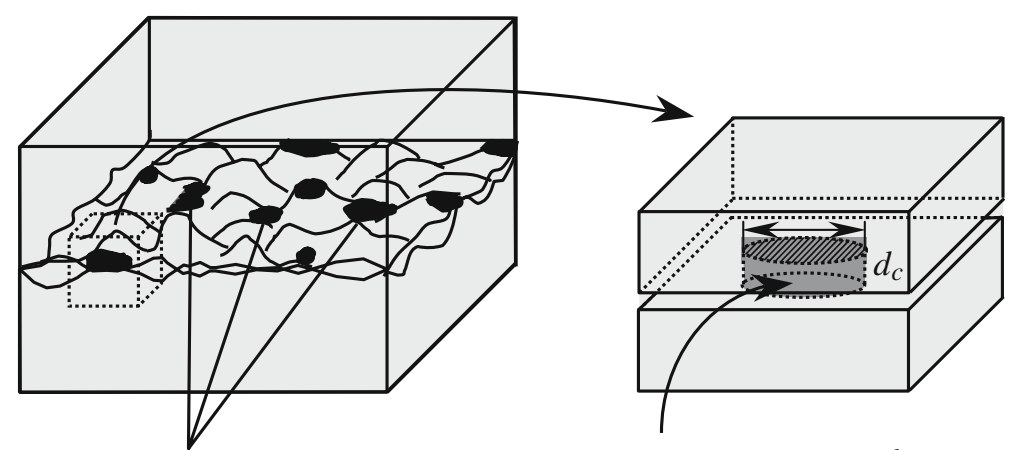

Asperity contacts

Local contact area, $A_{c}^{l}$

Figure 1. Idealized representation of the asperity contact condition. One representative contact area, $A_{\mathrm{c}}^{1}$ (on right side), represents the area of each asperity in contact (on left side), and is considered circular in shape, of diameter, $d_{\mathrm{c}}$. 
where $\sigma_{\text {eff }}$ is the average macroscopic effective stress.

Interactive processes of pressure solution and free-face dissolution irreversibly alter the geometry of the fracture surfaces, and the relation between fracture aperture and contact area may be defined to follow this modification of the fracture aperture and contact-area ratio within the tributary domain. The digitized fracture, obtained from profilometry, may constrain the relation between the fracture aperture and the contact-area ratio, and the relation is approximated by the regression curve, given by Yasuhara et al. (2004),

$$
\langle b\rangle=b_{\mathrm{r}}+\left(b_{0}-b_{\mathrm{r}}\right) \cdot \exp \left(-\left(R_{\mathrm{c}}-R_{\mathrm{c} 0}\right) / a\right),
$$

where $\langle b\rangle, b_{\mathrm{r}}$, and $b_{0}$ are the mean mechanical, residual and initial apertures, respectively. $R_{\mathrm{c}}$ is the contact-area ratio, and $a$ is a constant. This curve is adopted as a straightforward and representative relation between fracture contact area and aperture, to define the phenomenology of fracture sealing/gaping by pressure solution/free-face dissolution.

\subsection{COMPUTATIONAL PROCEDURE}

The individual processes of dissolution at asperity contacts, diffusion along interfacial water film, and free-face dissolution/precipitation are combined to define the progress of aperture reduction of the fracture with time. In the initial condition, a small representative contact area is set with the initial aperture of the fracture. An effective stress is applied, as amplified by the tributary geometry, and during time step $\Delta t$, appropriate magnitudes of mass dissolution at the representative contact area, diffusion, and freeface dissolution/precipitation are simultaneously evaluated from Equations (1)-(4), respectively. Physically, the dissolved mass evaluated from Equation (1) is supplied to the interface, and domain shortening (i.e., aperture reduction) proceeds as this mass passes along the interface by diffusion, as defined by Equation (2). Correspondingly, the volume diffused from the contacting asperities is given as,

$$
V_{\mathrm{t}}^{\mathrm{c}}=\sum_{\Delta t}\left(\frac{\mathrm{d} M_{\text {diff }}}{\mathrm{d} t}\right) \frac{\Delta t}{\rho_{\mathrm{g}}} .
$$

The volume removed from the contact area during the infinitesimal time interval, $\mathrm{d} t$, is given by,

$$
\mathrm{d} V_{\mathrm{t}}^{\mathrm{C}}=W L R_{\mathrm{c}} \mathrm{d} u
$$

where $W$ and $L$ are the width and the length of the sample, respectively. $\mathrm{d} u$ represents change in displacement during $\mathrm{d} t$. The relation between the 
mechanical aperture, $\langle b\rangle$, and displacement, $u$, can be defined by,

$$
\mathrm{d} u=-\frac{\mathrm{d}\langle b\rangle}{1-R_{\mathrm{c}}},
$$

Note that the negative sign is expressed as the sign convention that the aperture reduces as compaction proceeds. Substituting this into Equation (10), the cumulative volume removed from the contact area can be evaluated by integrating Equation (10) using Equation (8) with respect to the contact-area ratio, as,

$$
\begin{aligned}
V_{\mathrm{t}}^{\mathrm{C}}= & -W L \int_{R_{\mathrm{c} 0}}^{\left.R_{\mathrm{c}}\right|_{\mathrm{t}}} \frac{R_{\mathrm{c}}}{1-R_{\mathrm{c}}} \frac{\mathrm{d}\langle b\rangle}{\mathrm{d} R_{\mathrm{c}}} \mathrm{d} R_{\mathrm{c}} \\
= & \left(b_{0}-b_{\mathrm{r}}\right) \cdot W L \cdot \exp \left(-\left(1+\left.R_{\mathrm{c}}\right|_{\mathrm{t}}\right) / a\right) \cdot\left[\exp \left(\left(1+R_{\mathrm{c} 0}\right) / a\right)-\right. \\
& -\exp \left(\left(1+\left.R_{\mathrm{c}}\right|_{\mathrm{t}}\right) / a\right)+\exp \left(\left(R_{\mathrm{c} 0}+\left.R_{\mathrm{c}}\right|_{\mathrm{t}}\right) / a\right) / a \cdot\left(\operatorname{Ei}\left(\left(1-R_{\mathrm{c} 0}\right) / a\right)-\right. \\
& \left.\left.-\operatorname{Ei}\left(\left(1-\left.R_{\mathrm{c}}\right|_{\mathrm{t}}\right) / a\right)\right)\right]
\end{aligned}
$$

where $\operatorname{Ei}(x)$ is the exponential integral function and for the positive value of $x$ the function is expressed using the Puiseux series (Jeffreys and Jeffreys, 1988), as,

$$
\operatorname{Ei}(x)=\gamma+\ln x+\sum_{n=1}^{\infty} \frac{x^{n}}{n ! n},
$$

where $\gamma(=0.5772 \ldots)$ is the Euler-Mascheroni constant. Consequently, Equation (12) is rearranged as,

$$
\begin{aligned}
V_{\mathrm{t}}^{\mathrm{C}}= & \left(b_{0}-b_{\mathrm{r}}\right) \cdot W L \cdot \exp \left(-\left(1+\left.R_{\mathrm{c}}\right|_{\mathrm{t}}\right) / a\right) \cdot\left[\exp \left(\left(1+R_{\mathrm{c} 0}\right) / a\right)-\right. \\
& -\exp \left(\left(1+\left.R_{\mathrm{c}}\right|_{\mathrm{t}}\right) / a\right)+\exp \left(\left(R_{\mathrm{c} 0}+\left.R_{\mathrm{c}}\right|_{\mathrm{t}}\right) / a\right) / a \times \\
& \times\left(\ln \frac{1-R_{\mathrm{c} 0}}{1-\left.R_{\mathrm{c}}\right|_{\mathrm{t}}}+\sum_{n=1}^{\infty} \frac{\left.\left(1-R_{\mathrm{c} 0)^{n}-\left(1-\left.R_{\mathrm{c}}\right|_{\mathrm{t}}\right)^{n}}\right)\right]}{a^{n} n ! n}\right)
\end{aligned}
$$

Substituting this into Equation (9), the contact-area ratio is updated, and the average fracture aperture is also evaluated using Equation (8), given as,

$$
\left.\langle b\rangle_{\mathrm{c}}\right|_{\mathrm{t}}=10.0+13.5 \exp \left(-\left(\left.R_{\mathrm{c}}\right|_{t}-R_{\mathrm{c} 0}\right) / 6.5\right),
$$

where $\left.\langle b\rangle_{\mathrm{c}}\right|_{\mathrm{t}}$ denotes the updated fracture aperture mediated by dissolution and diffusion at contacting asperities, which does not include the contribution of free-face dissolution/precipitation. The volume dissolved from, or precipitated on the fracture void walls, $V_{\mathrm{t}}^{\mathrm{F}}$, is given by,

$$
V_{\mathrm{t}}^{\mathrm{F}}=\left.\langle b\rangle_{\mathrm{F}}\right|_{\mathrm{t}} \cdot W L=\sum_{\Delta t}\left(\frac{\mathrm{d} M_{\mathrm{diss}}^{\mathrm{FF}}}{\mathrm{d} t}-\frac{\mathrm{d} M_{\text {prec }}}{\mathrm{d} t}\right) \frac{\Delta t}{\rho_{\mathrm{g}}},
$$


where $\left.\left\langle b_{\mathrm{F}}\right\rangle\right|_{\mathrm{t}}$ represents the change in aperture due to free-face dissolution/precipitation. Note that the processes of dissolution and precipitation at the free surfaces assumes no contribution to changes in contact-area ratio and displacement, and merely alter the volume of the fracture void. Finally, the average fracture aperture accounting for the whole processes of pressure dissolution, interfacial diffusion, and free-face dissolution/precipitation, $\left.\langle b\rangle\right|_{t}$, is given as,

$$
\left.\langle b\rangle\right|_{\mathrm{t}}=\left.\langle b\rangle_{\mathrm{c}}\right|_{\mathrm{t}}+\left.\langle b\rangle_{\mathrm{F}}\right|_{\mathrm{t}} .
$$

Net dissolution from the fracture wall (Equation (3)) and resulting enlargement of the void cavity will compete with the closure occasioned by the shortening of the bridging asperity and precipitation on the fracture wall. The dominant process will prescribe whether the fracture gapes or seals (Figure 2). This deposition or dissolution on the free surface is controlled by the relative concentration differential between the pore fluid solution and the equilibrium concentration of that fluid (Equations (3) and (4)). Concurrently, dissolved mineral concentrations in the immobile fluid layer beneath the asperity contact, and the mobile fluid in the fracture void fluid are updated, as (Yasuhara et al., 2004),

$$
\left.C_{\mathrm{int}}\right|_{t+\Delta t}=\frac{\left(D_{1}+V_{\mathrm{p}} / 2 \Delta t\right) \cdot\left(\mathrm{d} M_{\mathrm{diss}} / \mathrm{d} t+V_{\mathrm{p}} /\left.4 \Delta t \cdot C_{\mathrm{int}}\right|_{t}\right)+D_{1} V_{\mathrm{p}} / 2 \Delta t \cdot C_{\mathrm{pore}}}{\left(D_{1} V_{\mathrm{p}} / 4 \Delta t\right) \cdot\left(D_{1}+V_{\mathrm{p}} / 2 \Delta t\right)-D_{1}^{2}},
$$

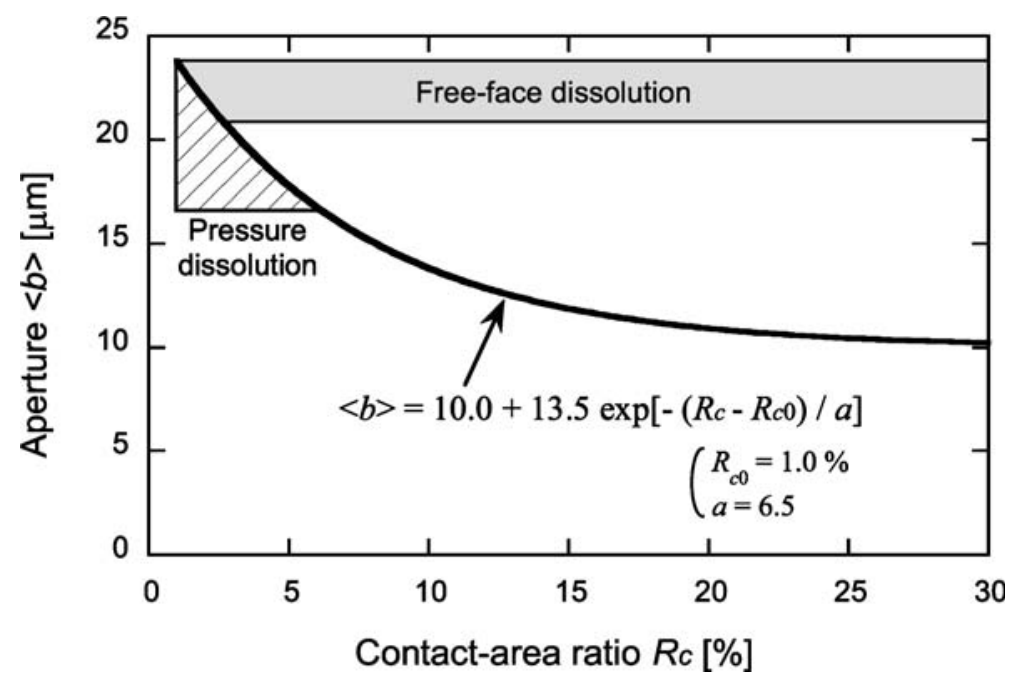

Figure 2. Relation between aperture and contact-area ratio. 
where,

$$
\begin{aligned}
& D_{1}=\frac{2 \pi \varpi D_{\mathrm{b}}}{\ln \left(d_{\mathrm{c}} / 2 a\right)}, \\
& C_{\text {pore }}=\frac{1}{Q}\left(\frac{\mathrm{d} M_{\text {diff }}}{\mathrm{d} t}+\frac{\mathrm{d} M_{\text {diss }}^{\mathrm{FF}}}{\mathrm{d} t}\right) \quad\left(\text { if } \quad C_{\text {pore }}<C_{\mathrm{eq}}\right), \\
& C_{\text {pore }}=\frac{1}{Q}\left(\frac{\mathrm{d} M_{\text {diff }}}{\mathrm{d} t}-\frac{\mathrm{d} M_{\mathrm{prec}}}{\mathrm{d} t}\right) \quad\left(\text { if } \quad C_{\text {pore }}>C_{\mathrm{eq}}\right),
\end{aligned}
$$

and $Q$ denotes the flow rate.

These relations are used iteratively to follow the evolution of dissolved concentrations in the fracture void, and resulting closure-history of the fracture.

\section{Replicating Experimental Observations}

This model for aperture evolution is applied to quantify observations of spontaneous aperture switching observed in flow through an artificial fracture in limestone (Polak et al., 2004). Water flow-though experiments in the dolomitic limestone (92 wt.\% calcite and $8 \mathrm{wt} . \%$ dolomite) are at constant temperature $\left(\sim 20^{\circ} \mathrm{C}\right)$, constant prescribed flow rate $\left(3.33 \times 10^{-8} \mathrm{~m}^{3} / \mathrm{s}\right.$ $(2 \mathrm{cc} / \mathrm{min}))$, and constant average effective stress $(\sim 3 \mathrm{MPa})$. The sample is sequentially circulated by sampled groundwater for $932 \mathrm{~h}$, denoted as stage I, followed by distilled water for $555 \mathrm{~h}$, denoted as consecutive stages II and III. The concentrations of calcium and magnesium, and the outlet and inlet $\mathrm{pH}$ are intermittently measured throughout the experiment, and changes in hydraulic aperture through the full $1497 \mathrm{~h}$ of the experiment are evaluated from concurrent measurements of pressure drop, as illustrated in Figures 3 and 4. The recorded evolution of fluid pressure drop is interpreted as a monotonic reduction in aperture, from 24 to $17 \mu \mathrm{m}$, during the initial circulation of groundwater (stage I), followed by an accelerated closure to a minimum aperture of $12 \mu \mathrm{m}$ at $1082 \mathrm{~h}$ (stage II), after the permeant is changed to distilled water. Subsequent to this, and absent any change in experimental conditions, measured pressure drop across the sample switches to net decrease with time (here defined as the onset of stage III). This is interpreted as a spontaneous switch from net fracture closure, to net gaping, absent any change in experimental conditions. We quantify this enigmatic behavior in the following, through the matches of both rates of fracture aperture change, and evolving mass concentrations in the pore fluid, using the previously developed model. These results are from a single experiment, but the form of this response is replicated in silicate rocks (Polak et al., 2003; Yasuhara et al., 2004, 2005 submitted). 

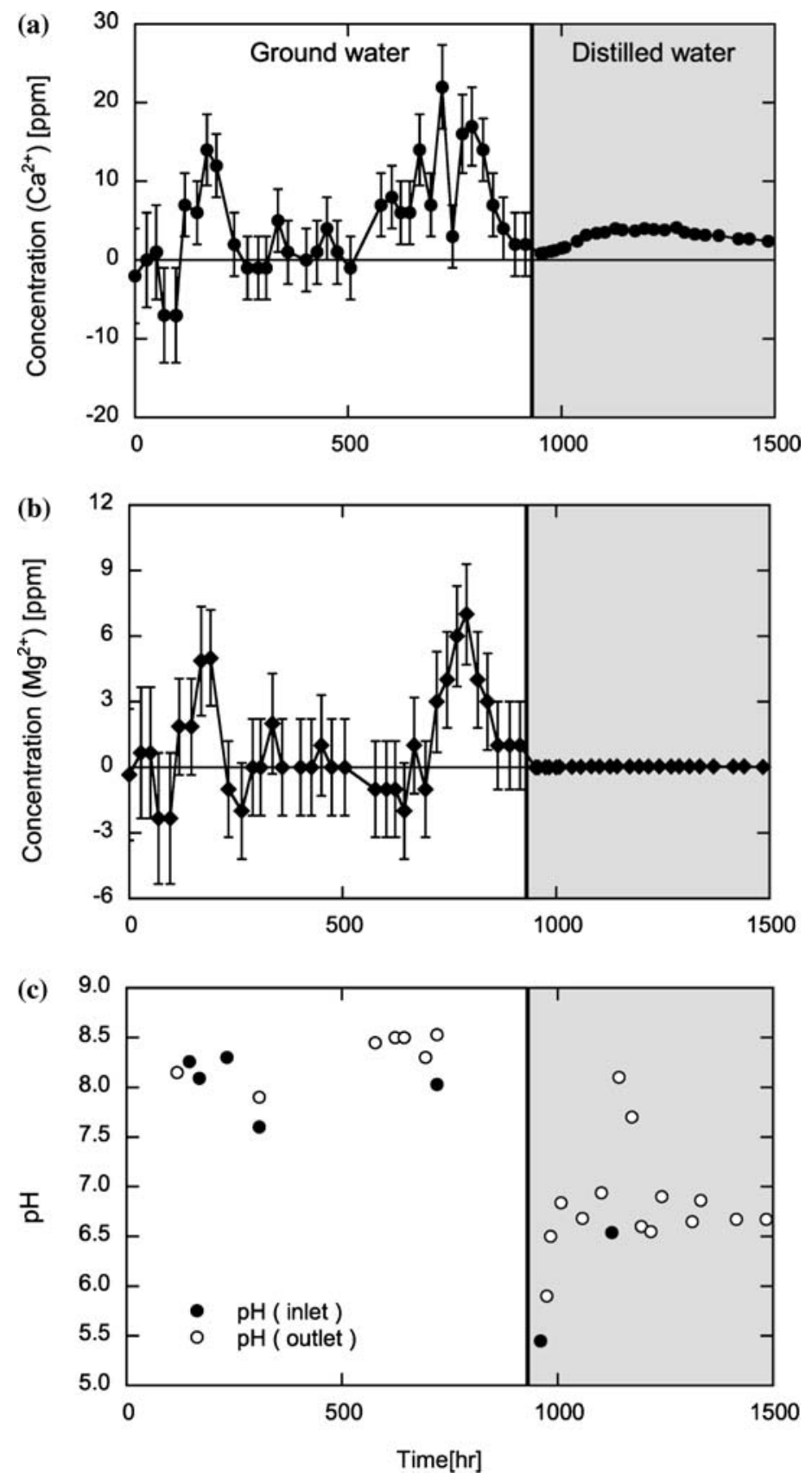

Figure 3. Concentration changes with time between the inlet and the outlet for (a) $\mathrm{Ca}$ and (b) $\mathrm{Mg}$, at inlet and outlet. Negative values correspond to mass left in the fracture and positive values to mass taken out of the system. Note the large error bars that are the result of the combined error of each sample. (c) Change in measured $\mathrm{pH}$ magnitudes at inlet and outlet, with time (after Polak et al. (2004)). 

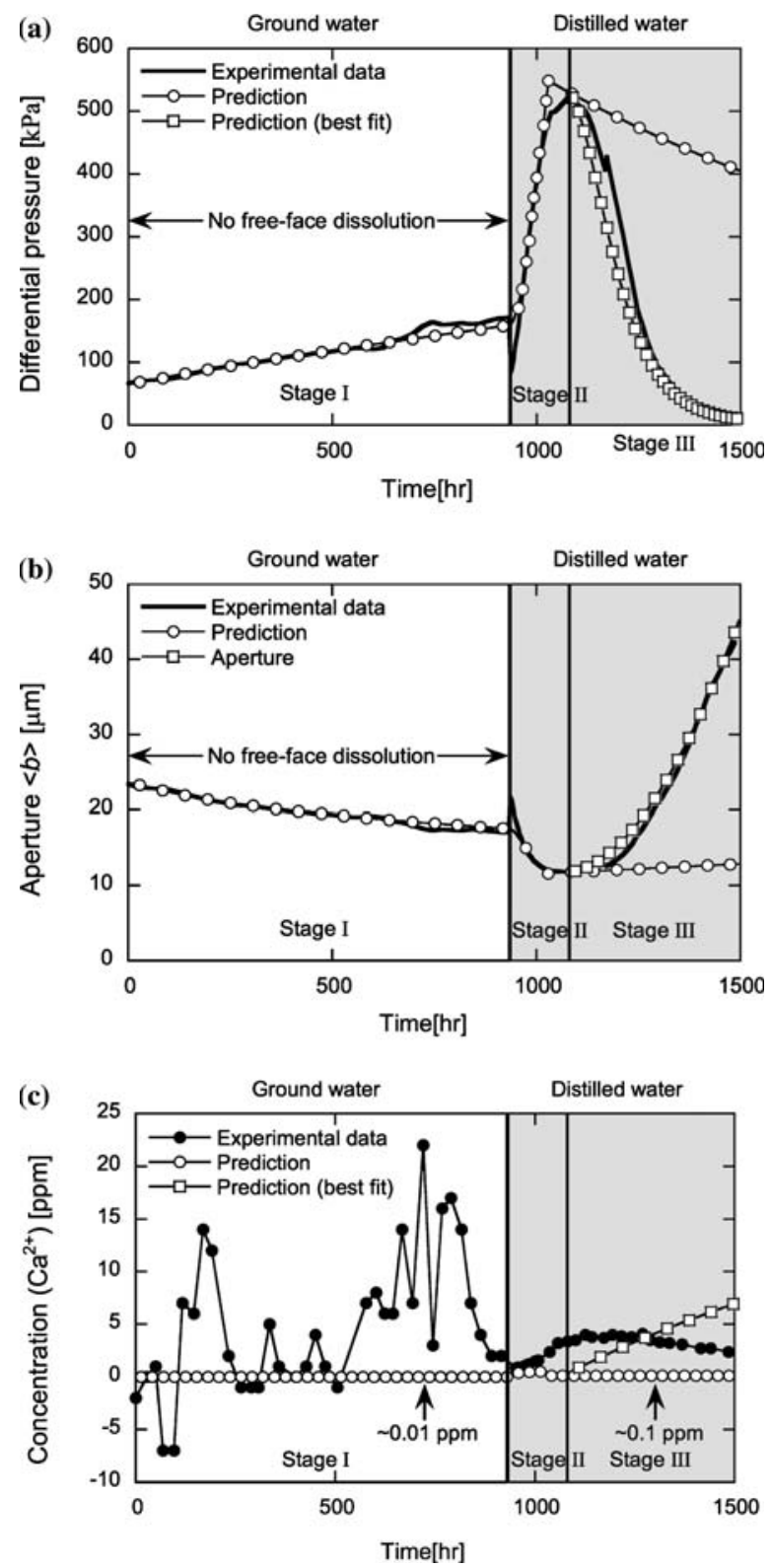

Figure 4. Comparisons between experimental data of Polak et al. [2004] and predictions of the current model; changes in (a) differential pressure, (b) aperture change, and (c) calcium concentrations (outlet minus inlet) with time. Open squares represent the predictions using parameters shown in Table I and modified values; with $k_{+/-}$decreased by a factor of 0.01 in stage I, with $k_{+/-}$increased by a factor of 2.0 in stages II and III, and the area of a fracture void, $A_{\text {pore, }}$ is decreased by a factor of $1 / 200$ in all stages. Open squares show the predictions modified by the factors of which $A_{\text {pore }}$ is linearly increased from $1 / 200$ to $60 / 200$ in stage III. These modifications are summarized in Table II. 


\subsection{AQUEOUS PARAMETERS}

The previously described mechanistic model is applied to represent the behavior observed in the $1497 \mathrm{~h}$ flow-through test described above (Polak et al., 2004). Observations to be matched are the evolution of mass concentrations of $\mathrm{Mg}$ and $\mathrm{Ca}$, and of the mean fracture aperture, or related pressure drop across the sample. During the flow circulation test, $\mathrm{Mg}$ concentrations recorded below the detection limit (Figure 3), and have little influence on mass removed. Conversely, $\mathrm{Ca}$ concentrations are large, but during the initial circulation of groundwater are largely incoherent, with large variations in influent concentrations, relative to the difference between input and output (Figure 3). With the circulation of distilled water, the difference in concentration across the sample becomes coherent, with effluent concentration differences climbing to $4.1 \mathrm{ppm}$. The mass of $\mathrm{Ca}$ removed is the primary component contributing to the observed change in pressure drop (or related aperture), and the presence of $\mathrm{Mg}$ contributes primarily in reducing the dissolution rate through the reaction rate constant, $k_{+}$.

The net rate of calcite dissolution, $R$, is given as (Plummer et al., 1978),

$$
R=k_{+, 1}\left(a_{\mathrm{H}^{+}}\right)+k_{+, 2}\left(a_{\mathrm{H}_{2} \mathrm{CO}_{3}^{*}}\right)+k_{+, 3}\left(a_{\mathrm{H}_{2} \mathrm{O}}\right)-k_{-}\left(a_{\mathrm{Ca}^{2+}}\right)\left(a_{\mathrm{HCO}_{3}^{-}}\right),
$$

where $k_{+, 1}, k_{+, 2}$, and $k_{+, 3}$ are first-order dissolution rate constants dependent on temperature, $k_{-}$is he precipitation rate constant dependent on both temperature and $p_{\mathrm{CO}_{2}} . a_{i}$ represents the activity for the component of $i$. The first two terms in this equation are functions of the bulk fluid activity of $\mathrm{H}^{+}$and the $p_{\mathrm{CO}_{2}}$, respectively. At $\mathrm{pH}>7.5$ and $p_{\mathrm{CO}_{2}}<0.1 \mathrm{~atm}$, $k_{+, 3}\left(a_{\mathrm{H}_{2} \mathrm{O}}\right)$ is the dominant term in the forward reaction, compared to $k_{+, 1}\left(a_{\mathrm{H}^{+}}\right)$and $k_{+, 2}\left(a_{\mathrm{H}_{2} \mathrm{CO}_{3}^{*}}\right)$, and $k_{+, 3}$ and $k_{-}$at $20^{\circ} \mathrm{C}$ in Equations (1), (3), and (4) are obtained from Plummer et al. (1978).

The diffusion coefficient of the calcium ion in pure water in Equation (2) is provided by Li and Gregory [1974]. The equilibrium concentration of the calcium ion in Equations (3) and (4) is predicted using the dissociation constants, $K_{1}, K_{2}, K_{\mathrm{CO}_{2}}$, and $K_{\mathrm{c}}$, of calcite (Harned and Scholes, 1941; Harnd and Davis, 1943; Jacobson and Langmuir, 1974; Kehew, 2001) at a temperature of $\sim 20^{\circ} \mathrm{C}$, a $p_{\mathrm{CO}_{2}}$ of $\sim 10^{-3.5} \mathrm{~atm}$ (atmospheric pressure) of the open system, and $\mathrm{pH}$ of $\sim 8.15$ (the average $\mathrm{pH}$ of the inlet fluid during groundwater circulation (Polak et al., 2004)), as summarized in Table I.

\subsection{FRACTURE PARAMETERS}

Parameters are ascribed to the fracture to represent the evolution of contact area with fracture closure that are consistent with the topography of the fracture surfaces in contact. The critical stress, $\sigma_{\mathrm{c}}$, in Equation (1) may be evaluated from the enthalpy of fusion and the melting temperature of calcite, 
Table I. Parameters used to represent the experimental results

\begin{tabular}{|c|c|c|c|c|c|c|c|}
\hline $\begin{array}{l}\text { Temperature } \\
T\left({ }^{\circ} \mathrm{C}\right)\end{array}$ & $\begin{array}{l}\text { Effective } \\
\text { stress } \\
\sigma_{\text {eff }} \\
(\mathrm{MPa})\end{array}$ & $\begin{array}{l}\text { Critical } \\
\text { stress } \\
\sigma_{\mathrm{c}} \\
(\mathrm{MPa})\end{array}$ & $\begin{array}{l}1 \text { Diffusion } \\
\text { path } \\
\text { width } \omega \\
(\mathrm{nm})\end{array}$ & $\begin{array}{l}\text { Diffusion } \\
\text { coefficient } \\
D_{\mathrm{b}} \\
\left(\mathrm{m}^{2} \mathrm{~s}^{-1}\right)\end{array}$ & $\begin{array}{l}\text { Dissolution } \\
\text { rate } \\
\text { constant } \\
k_{+} \\
\left(\mathrm{mol} \mathrm{m}{ }^{-2} \mathrm{~s}^{-1}\right)\end{array}$ & $\begin{array}{l}\text { Precipitation } \\
\text { rate } \\
\text { constant } \\
k_{-} \\
\left(\mathrm{mol} \mathrm{m} \mathrm{m}^{-2} \mathrm{~s}^{-1}\right)\end{array}$ & $\begin{array}{l}\text { Solubility } \\
\text { of calcium } \\
C_{\text {eq }}(\mathrm{ppm})\end{array}$ \\
\hline 20 & 3.0 & 20.0 & 4.0 & $6.93 \times 10^{-10}$ & $1.15 \times 10^{-6}$ & $1.21 \times 10^{-6}$ & 37.4 \\
\hline
\end{tabular}

although is difficult to constrain. The critical stress is not equivalent to the uniaxial compressive strength, but may be physically related to it. The uniaxial compressive strength of limestone is typically in the range 10-100 $\mathrm{MPa}$, and our calculations are conducted with a critical stress, $\sigma_{\mathrm{c}}$, of $20 \mathrm{MPa}$. The water film thickness, $\omega$, in Equation (2) is also an ill-constrained parameter. This value in the interface between the grain-to-grain contacts is of the order of $10^{-9} \mathrm{~m}$ and dependent on applied stress (e.g. Mullis, 1991; Heidug, 1995). An assumed thickness, $\omega$, of $4 \mathrm{~nm}$ is assumed in the following evaluations, with all parameters used in the model summarized in Table I.

For ease of discussion, we divide the experiment into three stages. Stage I is the circulation of groundwater $(0-932 \mathrm{~h})$, and stages II and III conform to the circulation of distilled water. Experimental conditions remain constant throughout stages II and III. Stage II (932-1082 h) is before the minimum aperture is reached, and stage III (1082-1487) is the period immediately following this attainment, as a wormhole forms (Polak et al., 2004). In the first stage of ground water circulation, the inlet calcium concentrations measured in the experiments are of the order of $40 \mathrm{ppm}$ (Figure 3), close to the equilibrium solubility of calcium at $20^{\circ} \mathrm{C}$ and one atmosphere. For stages II and III the calcium concentration is set to zero.

\subsection{MODIFIED PARAMETER MAGNITUDES}

Magnitudes of physical parameters are selected that are consistent with the two primary stages of the experiment: that involving the circulation of groundwater (stage I) and that involving distilled water (stages II \& III). The use of these scaled magnitudes is justified, following, and is summarized in Table II. Influent $\mathrm{Ca}$ concentrations of 40 and $0 \mathrm{ppm}$ are representative of the input fluids of $\mathrm{pH} \sim 8$ (stage I) and $\mathrm{pH} \sim 6$ (stages II \& III). Corresponding magnitudes of the precipitation rate constant, $k_{-}$, and the dissolution rate constant, $k_{+}$, are selected from Table I. Both the dissolution rate constant, $k_{+}$, of $1.15 \times 10^{-6} \mathrm{~mol} \mathrm{~m}^{-2} \mathrm{~s}^{-1}$, and the precipitation rate constant, $k_{-}$of $1.21 \times 10^{-6} \mathrm{~mol} \mathrm{~m}^{-2} \mathrm{~s}^{-1}$ are reduced by a factor of $10^{-2}$ to account for the 
Table II. Boundary conditions and modification of parameters used in the analysis.

\begin{tabular}{llll}
\hline Parameter & Test stages & & \\
\cline { 2 - 4 } & I & II & III \\
\hline $\begin{array}{l}\text { Influent concen- } \\
\text { tration (Ca), ppm }\end{array}$ & 40 & & \\
Influent pH & $\sim 8$ & 0 & 0 \\
$\begin{array}{l}\text { Precipitation } \\
\text { rate constant, } k_{-}\end{array}$ & $k_{-}(\mathrm{pH} \sim 8) \times 10^{-2}$ & $k_{-}(\mathrm{pH} \sim 6) \times 10^{-2}$ & $k_{-}(\mathrm{pH} \sim 6) \times 10^{-2}$ \\
& & $k_{-}(\mathrm{pH} \sim 6)=$ & $k_{-}(\mathrm{pH} \sim 6)=$ \\
& & $k_{-}(\mathrm{pH} \sim 8) \times 200$ & $k_{-}(\mathrm{pH} \sim 8) \times 200$ \\
Dissolution & & & \\
rate constant, $k_{+}$ & $k_{+}(\mathrm{pH} \sim 8) \times 10^{-2}$ & $k_{+}(\mathrm{pH} \sim 6) \times 10^{-2}$ & $k_{+}(\mathrm{pH} \sim 6) \times 10^{-2}$ \\
& & $k_{+}(\mathrm{pH} \sim 6)=k_{+}$ & $k_{+}(\mathrm{pH} \sim 6)=k_{+}$ \\
& & $(\mathrm{pH} \sim 8) \times 200$ & $(\mathrm{pH} \sim 8) \times 200$ \\
Contact area, $A_{\mathrm{c}}$ & $A_{\mathrm{c}}$ & $A_{\mathrm{c}}$ & $A_{\mathrm{c}}$ \\
$\begin{array}{l}\text { Fracture void area, } \\
A_{\text {pore }}\end{array}$ & & & \\
& $\left(A_{\mathrm{t}}-A_{\mathrm{c}}\right) \times 1 / 200$ & $\left(A_{\mathrm{t}}-A_{\mathrm{c}}\right) \times 1 / 200$ & $\left(A_{\mathrm{t}}-A_{\mathrm{c}}\right) \times 1 / 200$ \\
& & & $\left(A_{\mathrm{t}}-A_{\mathrm{c}}\right) \times 1 / 200 \rightarrow 60 / 200$ \\
\hline
\end{tabular}

influence of $\mathrm{Mg}$ on rate progress of dissolution and precipitation (e.g. Gautelier et al., 1999; Martinez and White, 1999; Brown and Glynn, 2003). When the circulating fluid is changed to distilled water, the rate constant increases by a factor of 200, accommodated by the presence of $\mathrm{H}^{+}$. This influence is applied consistently throughout the experimental data.

In addition to modifications in the rate constants, the contact areas and void areas of the fractures are also poorly constrained, and in part may be considered as scale dependent variables - reaction rates are known to decrease with increasing scale, as observed in differences between laboratory and field weathering rates (e.g. Swoboda-Colberg and Drever, 1993; Velbel, 1993). Correspondingly, the unmeasured fracture contact area, $A_{\mathrm{c}}$, is allowed to evolve naturally, but the surface area of the fracture void, $A_{\text {pore}}$, is set at $1 / 200$ th of the nominal void area, with total area defined as $A_{\mathrm{t}}$, and $A_{\text {pore }}=A_{\mathrm{t}}-A_{\mathrm{c}}$. For these selected parameters, comparison results of changes in differential pressure, aperture, and calcium concentrations between the experiment and the model are shown in Figure 4. For this consistent suite of parameters, the model accurately matches the observations and underlying processes for the change between permeants in stages I and II. It is also capable of following the spontaneous switch from permeability reduction to increase that occurs at $\sim 1030 \mathrm{~h}$, although the model response is muted over the observed behavior. Linearly increasing the surface area of the fracture void 60 -fold from 1/200th to 60/200ths 
in the period 1082-1487 h (stage III), results in an improved fit, but is an ad hoc modification. The reason for this adjustment is to accommodate the development of a wormhole (Polak et al., 2004), which is geometrically inconsistent with our chosen model - one that represents the flow system as a series of regular contacting asperities and tributary areas.

\section{Modeled Mass Removal and Permeability Response}

The evolution of fracture aperture with the progress of the experiment is represented by the prior model. We follow the measured change in aperture observed in the experiment, from an initial aperture of $24 \mu \mathrm{m}$; first closing, and then spontaneously gaping (Polak et al., 2004). Importantly, we provide no ad hoc mechanism to trigger the spontaneous change to gaping; rather this evolves as a natural consequence of the competition between agents that promote either asperity removal, or alternately free-face etching (reaction rate controlled dissolution), explicitly represented in the model.

The predicted rates of evolutions in differential pressure, aperture, and differential concentration in $\mathrm{Ca}$ (outlet minus inlet) are shown in Figure 4, together with the experimental measurements. This response is derived for the physical parameters identified in Table I, but modified in magnitude by the scaling parameters previously described, and included in Table II.

\subsection{STAGE I BEHAVIOR $(\mathrm{PH} \sim 8)$}

Where the initial fractional contact area is set to a nominal magnitude of $1 \%$, the evolving modeled aperture closely matches that evaluated from the flow data. The fracture evolution is insensitive to the choice of this starting magnitude of fracture contact area. The fracture reaches an intermediate contact area of $\sim 5 \%$ at the close of stage I ( $932 \mathrm{~h}$ ), corresponding to an aperture of $18 \mu \mathrm{m}$.

Measured and predicted $\mathrm{Ca}$ concentrations are compared in Figure 4(c). Evaluated concentration changes (outlet minus inlet) are of the order $\sim 0.01 \mathrm{ppm}$, and are absent the broad swings recorded in the experimental measurements (Polak et al., 2004), attributed to large relative measurement errors, and net dissolution from the matrix, unaccounted in the model.

Predicted $\mathrm{Ca}$ concentrations in the pore fluid are slightly larger than the equilibrium solubility, which results in nominal precipitation to the pore wall; the diminution in fracture aperture is less than $\sim 0.2 \mu \mathrm{m}$. Correspondingly, aperture evolution is controlled only by stress-mediated dissolution, with the mismatch between the predicted and measured concentrations shown in Figure 4(b).

The total volume of calcite $\left(\mathrm{CaCO}_{3}\right)$ net-removed during stage $\mathrm{I}$ is evaluated from the modeled aqueous efflux as $0.86 \mathrm{~mm}^{3}$ and this compares 
Table III. Estimated volumes of calcite $\left(\mathrm{CaCO}_{3}\right)$ from the test and model

\begin{tabular}{|c|c|c|c|c|c|c|}
\hline \multirow[t]{2}{*}{ Stage } & \multirow[t]{2}{*}{ Permeant } & \multirow[t]{2}{*}{ Time (h) } & \multicolumn{2}{|c|}{ Estimated volumes $\left(\mathrm{m}^{3}\right)$} & \multicolumn{2}{|c|}{ Predicted source* $(\%)$} \\
\hline & & & Experiment & Prediction & PS & FF \\
\hline I & Groundwater & $0-932$ & 262 & 0.86 & 100 & 0 \\
\hline II & Distilled water & $932-1082$ & 33 & 5.3 & 58 & 42 \\
\hline III & Distilled water & $1082-1487$ & 127 & 176 & 0 & 100 \\
\hline
\end{tabular}

*The relative dominance of predicted volumes between asperities (PS) and free-face dissolution (FF).

with the larger measured magnitude of $262 \mathrm{~mm}^{3}$ estimated from the measured efflux data (Table III). This larger flux is interpreted to result from the unconstrained dissolution from the matrix, apparent in the efflux concentration record between periods $70-190 \mathrm{~h}$ and $640-890 \mathrm{~h}$. This removal from the matrix interior is not directly related to the processes representing aperture reduction, and is not represented in the modeled behavior.

\subsection{STAGE II \& III BEHAVIOR (PH $\sim 6)$}

As distilled water is introduced, the fracture closure initially accelerates, and the contact area increases to $\sim 15 \%$ at the minimum aperture of $12 \mu \mathrm{m}$ $(1082 \mathrm{~h})$. The closure accelerates due to the increase in stress-mediated dissolution (Equation (22)) prompted by the lowering of $\mathrm{pH}$ in the influent fluid, as reflected in the elevated dissolution constant, $k_{+}$, apparent in Table II. During stage II, stress-mediated dissolution dominates, but this dominance transfers to free-face dissolution as the fracture topography and flow topology changes in response to dissolution. This transition is marked as the onset of stage III, but importantly, experimental variables are invariant throughout stages II and III. If model parameters are not changed, the fracture slowly gapes as free-face dissolution builds in the constricted void, relative to the effect of stress-mediated dissolution. This spontaneous switching in aperture, and related permeability, evolution is illustrated in Figure 4(b), although the modeled rate of aperture growth in this final stage is muted over observed behavior. The observed rate of aperture growth can only be matched if the surface area is arbitrarily increased over the period $1082-1487 \mathrm{~h}$, to represent the observed localization of mass removal within a restricted conduit. In this instance, the modeled response closely matches the measured growth in effective aperture from $\sim 12$ to $\sim 43 \mu \mathrm{m}$, although the assumed geometry of the fracture remains parallelsided rather than tubular in section (Polak, et al., 2004).

Throughout stage II, the contact-area ratio monotonically increases from $\sim 5$ to $\sim 15 \%$, proportionately decreasing the contact stresses, $\sigma_{\mathrm{a}}$, and 
increasing the mass diffusion length. These changes provide a reinforcing feedback in slowing the rate of pressure solution (i.e., aperture reduction), allowing free-face dissolution to dominate, and promote gaping of the fracture. For this sample, this transition occurs at $\sim 1028 \mathrm{~h}$, and marks the transition between stages II and III of the experiment.

As the fracture closes during stage II, predicted calcium concentrations are lower than those measured. Congruent with this, the calculated volume removed in stage II is $5.3 \mathrm{~mm}^{3}(58 \%$ removed from asperity contacts and $42 \%$ from the fracture void), representing only $17 \%$ of the measured removed volume of $33 \mathrm{~mm}^{3}$ (Table III).

The volume removed during stage III may be evaluated from the product of measured concentration and cumulative flow volume, to yield a magnitude of $127 \mathrm{~mm}^{3}$. This compares well with that evaluated from the product of modeled flow and modeled concentration, as $176 \mathrm{~mm}^{3}$ although the trends in modeled and measured concentrations, with time, are different.

The observations confirmed the development of a wormhole-like conduit in the sample (Polak et al., 2004), and the volume removed during stage III may be evaluated using the hydraulic data alone, and fitting a capillary tube model to the pressure drop (e.g., Bear, 1972), given as,

$$
Q=\frac{\pi r_{\mathrm{t}}^{4}}{8 \mu L} \Delta p \Leftrightarrow r_{\mathrm{t}}=\left(\frac{8 \mu L Q}{\pi \Delta p}\right)^{\frac{1}{4}},
$$

where $r_{\mathrm{t}}$ represents the radius of a single capillary tube. The maximum and minimum differential pressures recorded during stage III are 521 and $11 \mathrm{kPa}$, resulting in the radii of 65 and $170 \mu \mathrm{m}$, respectively. Subsequently, the evaluated volume is $\sim 8 \mathrm{~mm}^{3}$ and significantly underestimates the measured magnitude, suggesting that sources other than the fracture alone contribute to the mass flux.

\section{Implications}

The implications of this behavior may be examined by comparison with the reference behavior where flow rates and the nature of the circulating fluid are changed, specifically to examine their anticipated effect on the evolution of fracture aperture and transport characteristics. As apparent in the Sections 3 and 4 , groundwater $(\mathrm{pH} \sim 8)$ is pre-saturated with calcium and the contribution of free-face dissolution to aperture evolution is expected to be much smaller than that of pressure dissolution at contacting asperities. Also, distilled water $(\mathrm{pH} \sim 6)$ prompts the rates of dissolution processes at both of contacting asperities and free void walls.

Where groundwater $(\mathrm{pH} \sim 8)$ is circulated for the entire duration (Figure 5(a)), aperture monotonically decreases. There is no switch to 
permeability-increasing behavior as the rates of free-face dissolution are too small in comparison with the mass removal rate by pressure solution, to make an impact. Stress-mediated dissolution is the rate limiting step, and this rate slows as the local driving stress reduces as the asperity area concomitantly grows. Notably, for this mode of closure, changing flow rate has little influence on closure, since the process is rate limited by mass supply to the fracture void, and is controlled purely by stress magnitudes. The fracture asymptotes to the same minimum closure as exhibited where fluids are changed from groundwater to distilled water, this aperture being controlled by the combined closure stress and critical stress, $\sigma_{\mathrm{c}}$.

Where distilled water $(\mathrm{pH} \sim 6)$ is circulated for the entire duration (Figure 5(b)), beginning at the same original aperture as previous, of $24 \mu \mathrm{m}$, the same spontaneous switch in permeability is apparent as when the fluids were changed at $932 \mathrm{~h}$. However, for the circulation of distilled water, throughout, the switch in behavior occurs much earlier, driven by elevated diffusion of dissolved mass along the asperity contact. This elevated mass flux results from the lower native concentration of $\mathrm{Ca}$ within the circulating fluid. The resulting minimum aperture is identical to that obtained for the circulation of groundwater followed by distilled water - this minimum aperture is controlled by the mechanistic constraints of the mechanical properties, embodied in the selection of the critical stress, $\sigma_{\mathrm{c}}$. As the minimum aperture is approached, fluid flow rate has little influence on the rate of closure. After the minimum aperture is reached, fracture gaping is controlled by the free-face dissolution rate constant for flow rates equal to, and greater than, the original test $(2 \mathrm{cc} / \mathrm{min})$. Where the flow rate is dropped by two orders of magnitude, then the fluid advective flux influences the dissolution and mass removal rates, and the rate of fracture gaping is correspondingly reduced.

Where groundwater $(\mathrm{pH} \sim 8)$ is first circulated through the sample followed by distilled water $(\mathrm{pH} \sim 6)$, the influence of changing flow rates is identified in Figure 5(c). Notably, flow rate has no influence on behavior before minimum aperture is reached, as this behavior is predominantly controlled by stress-mediated dissolution. Once the circulating fluid is changed to distilled water, the fracture aperture tracks identically to Figure 5(b). Similarly, at high flow rates aperture evolution is rate limited by the dissolution rate constant, and at low flow rates by the advective flux.

Apparent from the respective rates of aperture gaping and aperture closure is the propensity for dominance by dissolution and precipitation over stress-mediated effects. In carbonates, the rates of dissolution are significantly higher than those for stress-mediated dissolution, unless excess stresses are much higher than represented here $(\sim 3 \mathrm{MPa})$. The stability band for stress-effects to dominate is restricted to flows at concentrations close to the equilibrium concentration of calcite in water. This requirement 

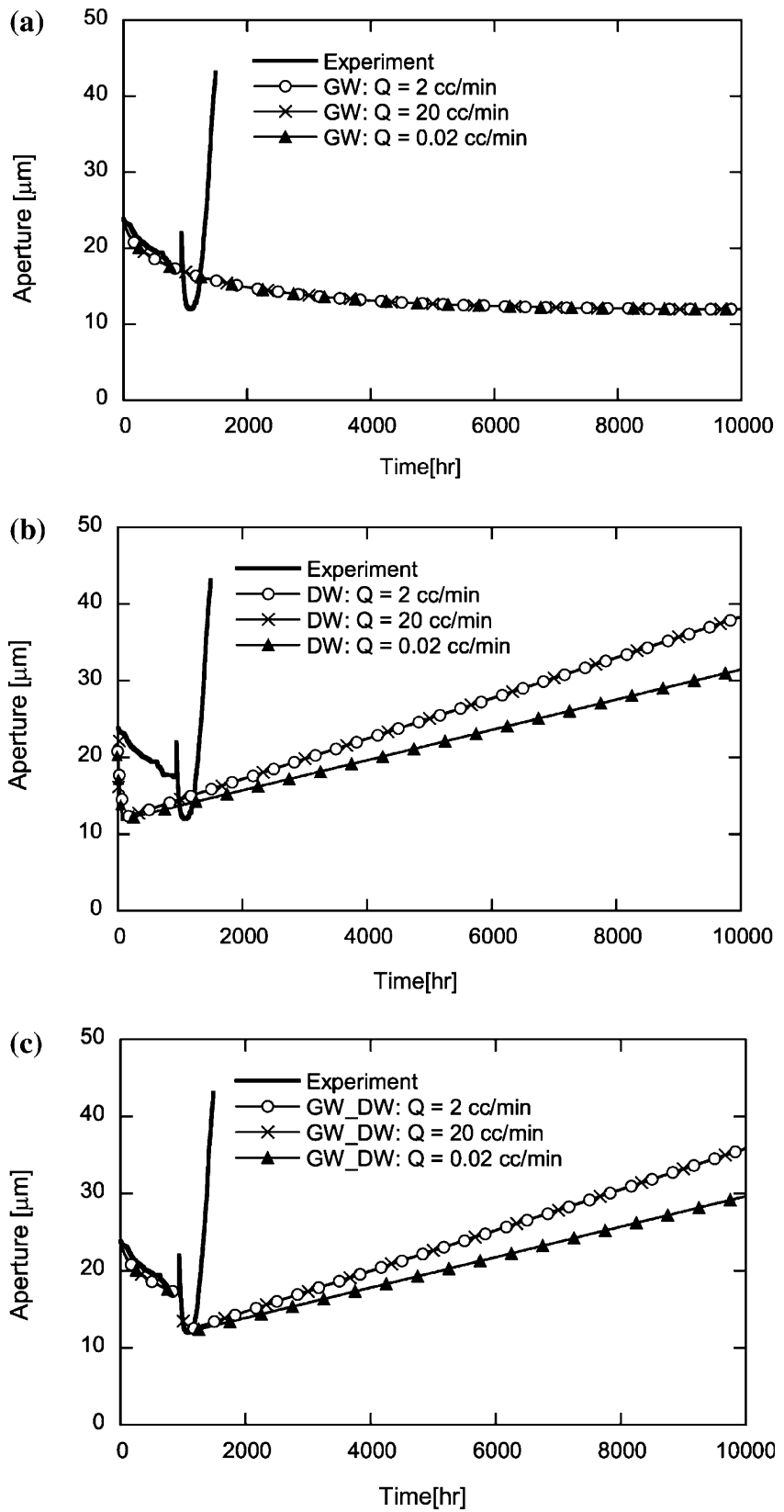

Figure 5. Comparisons of changes in aperture over extended periods of time where the flow rate and nature of the circulated fluid are changed. Flow rates are increased by an order of magnitude $(20 \mathrm{cc} / \mathrm{min})$ and decreased by two orders of magnitude $(0.02 \mathrm{cc} / \mathrm{min})$, for the conditions of: (a) circulation of groundwater $(\mathrm{pH} \sim 8)$ for the entire period, (b) circulation of distilled water $(\mathrm{pH} \sim 6)$ for the entire period, and (c) circulation of groundwater $(\mathrm{pH} \sim 8$ for $932 \mathrm{~h}$ ) followed by distilled water $(\mathrm{pH} \sim 6$ for $\mathrm{t}>932 \mathrm{~h})$. 
is met for the early circulation of groundwater in this experiment, but clearly not for the later circulation of distilled water, when, following a period of readjustment, the behavior switches to net gaping.

\section{Conclusions}

A mechanistic model is developed to explain spontaneous switching in permeability changes observed in a fracture in carbonate, that occur without changes in environmental conditions of average stress or chemical potential of the influent fluid. The observed switch from net fracture closure, to net gaping, is shown compatible with competing mechanisms of pressure solution and free-face dissolution. As the fracture closes, flow is localized within a progressively smaller cross-section of the fracture, reducing the contribution from pressure solution, and isolating the source of the mass removed. This source region for dissolved mass ultimately becomes a wormhole.

The evolution of this process may be followed by representing the chemical interactions of the individual contributing processes, and transport within the system. These important processes include dissolution at asperity contacts, interfacial diffusion of dissolved mass along the asperity-to-asperity contact boundary, followed by either advection out of the system, or precipitation at the fracture-void surface. Where the water circulating in the fracture-void is undersaturated, an additional mass will be removed from the fracture-void wall. These processes are linked to the evolution of fracture aperture, and related fluid transport parameters, by a geometric model of the fracture that relates fracture aperture and contact-area. Together, the transport system and geometric model enable the progress of fracture aperture and mass concentration in the pore fluid to be followed under arbitrary conditions of applied stress, temperature, and $\mathrm{pH}$.

This model is shown capable of replicating experimental observations recovered from circulation of water in a stressed fracture in limestone (Polak et al., 2004). Matches of changes in sample permeability with time, and related aperture change, are congruent with observations, although calcium concentrations in the effluent fluid are underestimated during the initial circulation of groundwater (stage I), but are better constrained in the late test during the circulation of distilled water (stages II and III); the predicted and measured mass volume effused from the system are 181 and $160 \mathrm{~mm}^{3}$, respectively.

In the first stage of groundwater circulation $(0-932 \mathrm{~h})$ the fracture aperture monotonically reduces. The process is controlled only by the dominant process of pressure solution, with free-face dissolution contributing no change in the impedance (i.e., related aperture or permeability). The calcium concentrations in the effluent fluid are predicted to be slightly larger than the equilibrium solubility, and result in the activation of precipitation. 
However, the precipitated mass is trivial and causes no observable change in aperture. In the second stage of distilled water circulation (932-1082 h) the lower $\mathrm{pH}$ in the pore fluid $(\mathrm{pH} \sim 6$ ) results in accelerated rates of aperture reduction, and the low calcium concentrations $(\sim 0.5 \mathrm{ppm})$ activate free-face dissolution. The maximum flow impedance is predicted around $1028 \mathrm{~h}$, close to the experimentally measured time of $1082 \mathrm{~h}$, as, for the first time, the effect of free-face dissolution exceeds that of pressure solution. This results as local stresses reduce, in response to the widening of asperity contacts, even though applied mean stress remains constant.

In the final stage (1082-1497 h), impedance abruptly decreases until the experiment is terminated, with free-face dissolution as the dominant mechanism of mass removal. A single through-going conduit is observed to form in the experiment, although the lumped geometry assumed in the analysis is incapable of appropriately representing this process. Despite this, representation of the fracture by the behavior of a single representative asperity within a tributary area is capable of recording the spontaneous switch from net fracture closure to net widening. To accurately replicate observed response, the evolution of the fracture surface area must be artificially augmented to increase the contribution of free-face dissolution on the evolving wormhole. The evolution of a wormhole may only be represented if the distributed response of dissolution over the fracture contact area is adequately represented - a feature not apparent in this lumped-parameter representation.

\section{Acknowledgements}

This work is a result of partial support under grants DOE-BES-DEFG02-00ER15111, DOE-Geo thermal-DE-FG 36-04 GO14289, and ARC DP0209425. This support is gratefully acknowledged. The comments of anonymous reviewers significantly contributed to the quality of the final manuscript.

\section{Appendix A: Derivation of Dissolution Mass Flux at Contacting Asperity}

Pressure solution incorporates the serial processes of dissolution, diffusion along the interfacial water film, and then by precipitation from the pore fluid to the pore wall. Dissolution creep controls the first of these serial processes through stress-mediated dissolution at contacting asperities. Dissolution at the contacting asperities provides a source of mass that may be redistributed by diffusion along an inter-asperity water layer. The rate of compaction is influenced both by the absolute rate of mass diffusion along this interface, and by the lengthening of the diffusion path, as the asperities interpenetrate, and the contact area grows. 
In the case of the compaction behavior in grain aggregate due to pressure solution, the strain rate caused by dissolution at grain contacts, analogous to contacting asperities in a fracture, is defined as (Revil, 1999 modified from Raj, 1982),

$$
\dot{\varepsilon}_{\mathrm{diss}}=\frac{3 V_{\mathrm{m}} k_{+}}{R T d}(-\Delta \mu),
$$

where $\dot{\varepsilon}_{\text {diss }}$ is the strain rate, $V_{\mathrm{m}}$ is the molar volume, $k_{+}$is the dissolution rate constant, $R$ is the gas constant, and $T$ is the temperature of the system. $d$ represents the grain diameter, and may be regarded as the tributary length to fracture compaction. In this, $\Delta \mu$ represents the chemical potential difference between the compressive site of contact (either the grain-to-grain or asperity) and the less-stressed site of the pore wall, and is the motive force driving pressure solution (the negative sign is expressed because of the thermodynamic convention; $\left.\Delta \mu=\mu_{\text {last }}-\mu_{\text {initial }}\right)$. Applying non-hydrostatic and non-equilibrium thermodynamics, the chemical potential at the stressed contact, $\mu$, is defined as (Heidug, 1995),

$$
\mu=\left(\sigma_{\mathrm{a}}+p\right) V_{\mathrm{m}}+f-2 H \gamma \cdot V_{\mathrm{m}},
$$

where $\sigma_{\mathrm{a}}$ is the disjoining pressure (e.g., Tada et al., 1987) equal to the amount by which the pressure acting at the contacts exceeds the hydrostatic pore pressure, $p$ is the pore pressure, and $f$ is the molar Helmholtz free energy which may consist of the elastic and plastic strain energy. The last term on the right-hand side represents a surface energy at the contact, where $H$ is the mean local curvature of the solid-fluid interface and $\gamma$ is the specific interfacial energy. Since pressure acting on the void wall is the pore pressure, the chemical potential difference, $\Delta \mu$, for the solute is given by,

$$
-\Delta \mu=\sigma_{\mathrm{a}} V_{\mathrm{m}}+\Delta f-2 H \gamma \cdot V_{\mathrm{m}},
$$

where $\Delta f$ is the molar Helmholtz free energy difference between the stressed contacts and the free pore walls.

For simplicity, in a uniaxial compressive condition and assuming that the stress applied at the contact area does not vary with the location in the interface, the disjoining pressure, $\sigma_{\mathrm{a}}$, is given by,

$$
\sigma_{\mathrm{a}}=\frac{\sigma_{\mathrm{eff}}}{R_{\mathrm{c}}}
$$

where $\sigma_{\text {eff }}$ is the effective stress, defined as the average stress exceeding the pore pressure, and $R_{\mathrm{c}}\left(0<R_{\mathrm{c}}<1\right)$ is the ratio of the contact area to the maximum cross sectional area normal to the applied stress. When the system reaches thermodynamic equilibrium, the chemical potential difference will be 
zero and stress applied at the contact area, $\sigma_{\mathrm{a}}$, will reach the critical stress, $\sigma_{\mathrm{c}}$. Therefore from Equations (A3) and (A4) these yield at equilibrium,

$$
\sigma_{\mathrm{a}}^{\mathrm{eq}}=\sigma_{\mathrm{c}}=\frac{\sigma_{\mathrm{eff}}}{R_{\mathrm{c}}^{\mathrm{eq}}}=2 \gamma H^{\mathrm{eq}}-\frac{\Delta f^{\mathrm{eq}}}{V_{\mathrm{m}}},
$$

where the superscript eq denotes the equilibrium condition for each term. Substituting Equation (A5) into the chemical potential relation of Equation (A3), yields,

$$
-\Delta \mu \approx\left(\sigma_{\mathrm{a}}-\sigma_{\mathrm{c}}\right) \cdot V_{\mathrm{m}},
$$

and provides a threshold stress, $\sigma_{\mathrm{c}}$, for the initiation of pressure solution. Substituting this into Equation (A1), the compaction strain rate through dissolution at the contacts is given by,

$$
\dot{\varepsilon}_{\text {diss }}=\frac{3 V_{\mathrm{m}}^{2} k_{+}}{R T d}\left(\sigma_{\mathrm{a}}-\sigma_{\mathrm{c}}\right) .
$$

The appropriateness of a critical stress where pressure solution ceases (i.e. the validity of Equation (A7)), is supported by the experimental data (see Table I and Figure 2 in Yasuhara et al. (2003)).

In defining mass redistribution, it is sometimes convenient to relate dissolution mass fluxes, $\mathrm{d} M_{\mathrm{diss}}^{\mathrm{PS}} / \mathrm{d} t$, to strain rates. In the one-dimensional case the strain rate is defined as,

$$
\dot{\varepsilon}_{\text {diss }}=\frac{1}{d} \frac{\Delta d}{\Delta t} .
$$

Using the dissolution mass flux, $\mathrm{d} M_{\text {diss }}^{\mathrm{PS}} / \mathrm{d} t, \Delta d / \Delta t$ is expressed as,

$$
\frac{\Delta d}{\Delta t} \approx \frac{\mathrm{d} M_{\text {diss }}}{\mathrm{d} t} \cdot \frac{1}{\rho_{\mathrm{g}}} \cdot \frac{1}{(\pi / 4) d_{\mathrm{c}}^{2}}
$$

where $\rho_{\mathrm{g}}$ is the density, $d_{\mathrm{c}}$ is the diameter of the contacts, and the term of $\left(\pi / 4 d_{\mathrm{c}}^{2}\right)$ represents the contact area at the interface. From Equation (A7)(A9), the dissolution mass flux, $\mathrm{d} M_{\mathrm{diss}}^{\mathrm{PS}} / \mathrm{d} t$, is then given by,

$$
\frac{\mathrm{d} M_{\mathrm{diss}}}{\mathrm{d} t}=\frac{3 \pi V_{\mathrm{m}}^{2}\left(\sigma_{\mathrm{a}}-\sigma_{\mathrm{c}}\right) k_{+} \rho_{\mathrm{g}} d_{\mathrm{c}}^{2}}{4 R T} .
$$

\section{References}

Bear, J.: 1972, Dynamics of Fluids in Porous Media, Dover, Mineola, NY, pp. 162-165.

Brown, J. G. and Glynn, P. D.: 2003, Kinetics dissolution of carbonates and Mn oxides in acidic water: measurement of in situ field rates and reactive transport modeling, Appl. Geochem. 18, 1225-1239.

Dijk, P. E. and Berkowitz, B.: 2000, Buoyancy-driven dissolution enhancement in rock fractures, Geology 28(11), 1051-1054. 
Dijk, P. E., Berkowitz, B. and Yechieli, Y.: 2002, Measurements and analysis of dissolution patterns in rock fractures, Water Resour. Res. 38(2), 10.1029/2001WR000246.

Dreybrodt, W.: 1998, Principles of karst evolution from initiation to maturity and their relation to physics and chemistry, in: Yuan, D. X. and Liu Z. H. (eds), Global Karst Correlation, Science Press, Beijing, pp. 33-49.

Dreybrodt, W. and Buhmann, D.: 1991, A mass transfer model for dissolution and precipitation of calcite from solutions in turbulent motion, Chem. Geol. 90, 107-122.

Durham, W. B., Bourcier, W. L. and Burton, E. A.: 2001, Direct observation of reactive flow in a single fracture, Water Resour. Res. 37, 1-12.

Gautelier, M., Oelkers, E. H. and Schott, J.: 1999, An experimental study of dolomite dissolution rates as a function of $\mathrm{pH}$ from -0.5 to 5 and temperature from 25 to $80^{\circ} \mathrm{C}$, Chem. Geol. 157, 13-26.

Harned, H. S. and Davism, R.: 1943, The ionization constant of carbonic acid in water and the solubility of carbondioxide in water and aqueous salt solutions from 0 to $50{ }^{\circ} \mathrm{C}$, J. Am. Chem. Soc. 65, 2030-2037.

Harnd, H. S. and Scholes, S. R.: 1941, The ionization constant of $\mathrm{HCO}_{3}^{-}$from 0 to $50^{\circ} \mathrm{C}$, J. Am. Chem. Soc. 63, 1706-1709.

Heidug, W. K.: (1995), Intergranular solid-fluid phase transformations under stress: The effect of surface forces, J. Geophys. Res. 100, 5931-5940.

Jacobson, R. L. and Langmuir, D.: 1974, Dissociation constants of calcite and $\mathrm{CaHCO}_{3}^{+}$ from 0 to $50^{\circ} \mathrm{C}$, Geochim. Cosmochim. Acta, 38, 301-318.

Jeffreys, H. and Jeffreys, B. S.: 1988, Methods of Mathematical Physics, Cambridge University Press, Cambridge, England, pp. 470-472.

Kehew, A. E.: 2001, Carbonate mineral equilibria, In Applied Chemical Hydrogeology, Prentice Hall Press, Upper Saddle River, N.J. pp. 53-59.

Li, Y. H. and Gregory, S.: 1974, Diffusion of ions in sea water and in deep-sea sediments, Geochim. Cosmochim. Acta, 38, 703-714.

Lin, W., Roberts, J., Glassley, W. and Ruddle, D.: 1997, Fracture and matrix permeability at elevated temperatures, Workshop on significant issues and available data, Nearfield/Altered-zone coupled effects expert elicitation project, San Francisco, November.

Liu, X., Ormond, A., Bartko, K., Li, Y. and Ortoleva, P.: 1997, A geochemical reaction-transport simulator for matrix acidizing analysis and design, J. Pet. Sci. Eng. 17, 181-196.

Martinez, M. I. and White, W. B.: 1999, A laboratory investigation of the relative dissolution rates of the Iirio Limestone and the Isla de Mona Dolomite and implications for cave and karst development on Isla de Mona, J. Cave Karst Stud. 61, 7-12.

Moore, D. E., Lockner, D. A., Byerlee, J. D.: 1994, Reduction of permeability in granite at elevated temperatures, Science 265, 1558-1561.

Mullis, A. M.: 1991, The role of silica precipitation kinetics in determining the rate of quartz pressure solution, J. Geophys. Res. 96, 10007-10013.

Palmer, A. N.: Origin and morphology of limestone caves, Geol. Soc. Am. Bull. 103, 1-21, 1991.

Plummer, L. N., Wigley, T. M. L. and Parkhurst, D. L.: 1978, The kinetics of calcite dissolution in $\mathrm{CO}_{2}$-water systems at $5^{\circ}$ to $60^{\circ} \mathrm{C}$ and 0.0 to $1.0 \mathrm{~atm} \mathrm{CO}_{2}, \mathrm{Am}$. J. Sci. 278, 179-216.

Polak, A., Elsworth, D., Yasuhara, H., Grader, A. and Halleck, P.: 2003, Permeability reduction of a natural fracture under net dissolution by hydrothermal fluids, Geophys. Res. Lett. 30(20), 2020, doi:10.1029/2003GL017575.

Polak, A., Elsworth, D., Liu, J. and Grader, A. S.: 2004, Spontaneous switching of permeability changes in a limestone fracture with net dissolution, Water Resour. Res. Vo. 40, W03502, doi:10.1029/2003WR002717. 
Polyak, V. J., McIntosh, W. C., Güven, N. and Provencio, P.: 1998, Age and origin of Carlsbad cavern and related caves from ${ }^{40} \mathrm{Ar} /{ }^{39} \mathrm{Ar}$ of alunite, Science 279, 1919-1922.

Raj, R.: 1982, Creep in polycrystalline aggregates by matter transport though a liquid phase, J. Geophys. Res. 87, 4731-4739.

Revil, A.: 1999, Pervasive pressure-solution transfer: a poro-visco-plastic model, Geophys. Res. Let. 26, 255-258.

Swoboda-Colberg, N. G. and Drever, J. I.: 1993, Mineral dissolution rates in plot-scale field and laboratory experiments, Chem. Geol. 105(1-3), pp. 51-69.

Tada, R., Maliva, R. and Siever, R.: 1987, Rate laws for water-assisted compaction and stress-induced water-rock interaction in sandstones, Geochim. Cosmochim. Acta 51, 22952301.

Tenthorey, E., Cox, S. F. and Todd, H. F.: 2003, Evolution of strength recovery and permeability during fluid-rock reaction in experimental fault zones, Earth and Plane. Sci. Lett. 206, 161-172.

Velbel, M. A.: 1993, Constancy of silicate-mineral weathering-rate ratios between natural and experimental weathering: implications for hydrologic control of differences in absolute rates, Chem. Geol. 105(1-3), pp. 89-99.

Yasuhara, H., Elsworth, D and Polak, A., 2003, A mechanistic model for compaction of granular aggregates moderated by pressure solution, J. Geophys. Res., 109 (B11), 2530, DOI: $10.1029 / 2003 J B 002536$

Yasuhara, H., Elsworth, D. and Polak, A.: 2004, Evolution of permeability in a natural fracture: Significant role of pressure solution, J. Geophys. Res. 109(B3), B03204, doi:10.1029/2003JB002663. 